\title{
Mapas conceituais: um curso de capacitação para professores da educação básica
}

\author{
Luiz Marcelo Darroz \\ Universidade de Passo Fundo | Brasil \\ ldarroz@upf.br \\ Jucelino Cortez \\ Universidade de Passo Fundo | Brasil \\ jucelino@upf.br
}

\section{Resumo}

Este trabalho apresenta uma experiência bemsucedida de capacitação docente. Trata-se de um curso de extensão realizado com um grupo de professores da educação básica, cujo objetivo era apresentar/fortalecer a metodologia de mapeamento conceitual para a promoção da aprendizagem significativa dos conceitos trabalhados em sala de aula. 0 curso ocorreu em cinco encontros e os resultados fortalecem a suposição de que uma metodologia com enfoque em um conteúdo significativo ao professor é fundamental para despertar-lhe o interesse para novas aprendizagens metodológicas que os auxiliam na construção de significado do que pretende ensinar..

\section{Palavras-chave}

Mapas Conceituais; Aprendizagem Significativa; Capacitação de professores. 


\section{Introdução}

Atualmente, a educação é tema constante na mídia, pois vivemos uma época em que todos a percebem como primordial para o desenvolvimento social e o progresso de um país. Se um país não a pautar em seu planejamento como prioridade de governo, com certeza, seu crescimento será prejudicado, tendo em vista que uma nação próspera é uma nação essencialmente educada e com excelente educação.

Em vista do exposto, diversas ações têm sido desenvolvidas em todo o Brasil, buscando qualificar o processo de ensino-aprendizagem, no entanto, o que tem se percebido nas escolas é que ainda não se conseguiu alcançar os objetivos almejados. Na metodologia hoje utilizada, o professor permanece no centro do processo, cabendo-lhe a transmissão dos conhecimentos mediante a repetição automatizada de procedimentos em situações artificiais, desvinculadas da realidade. Os estudantes, por sua vez, desempenham o papel de coadjuvantes, competindo-lhes observar e receber os conteúdos para, posteriormente, reproduzi-los em avaliações que buscam mensurar os conhecimentos adquiridos (NEVES, 2012). Essa metodologia pode ser considerada um dos principais entraves no processo de aprendizagem, promovendo uma educação monológica, linear, fragmentada e mecanizada.

Com o advento da Lei de Diretrizes e Bases da Educação Nacional (Lei no 9.394/97) e com a publicação dos Parâmetros Curriculares para o Ensino Médio (PCN) e dos PCN+, o que se espera é que a formação do aluno tenha como alvo principal a aquisição de conhecimentos básicos, a preparação científica e a capacidade de utilizar as diferentes tecnologias relativas às áreas de atuação. Por isso, propõe-se aos professores formar alunos que sejam capazes de pesquisar, buscar informações, analisá-las e selecioná-las; de aprender, criar, formular, em vez de simplesmente memorizar. Nessa nova concepção, é fundamental que as metodologias de ensino aplicadas em sala de aula busquem facilitar o desenvolvimento dos conteúdos, em uma perspectiva interdisciplinar e contextualizada, promovendo nos estudantes uma aprendizagem verdadeiramente significativa.

Diante dessa realidade, o presente texto relata a experiência vivenciada por um grupo de professores da educação básica em um curso de extensão que buscou apresentar diferentes estratégias de ensino que podem fazer uso dos mapas conceituais para promover a aprendizagem significativa como recurso, na tentativa de sanar as dificuldades enfrentadas na escola.

\section{Referencial teórico: a aprendizagem significativa e os mapas conceituais}


Mapas conceituais: um curso de capacitação para professores da educação básica

A aprendizagem significativa de Ausubel, segundo Moreira (1999), prioriza a aprendizagem cognitiva, que, nessa teoria, é considerada como um processo pelo qual o novo conhecimento se articula com uma determinada estrutura cognitiva prévia, denominada "subsunçora". A estrutura cognitiva, por sua vez, é entendida como o conjunto de conteúdos informacionais e a maneira como esses se organizam na mente de um indivíduo. Já os subsunçores correspondem a conceitos ou ideias previamente existentes na estrutura cognitiva, capazes de tornarem-se "pontos de ancoragem", em que as novas informações encontrarão um modo de se integrar àquilo que a pessoa já conhece.

A aprendizagem significativa contrapõe-se, fundamentalmente, à aprendizagem mecânica, na medida em que, na primeira, a nova informação interage com algum subsunçor existente na estrutura cognitiva. Na segunda, a nova informação é armazenada de maneira arbitrária e literal, não interagindo com informações prévias e, assim, pouco ou nada contribui para sua elaboração e diferenciação. Conforme Ausubel (apud MOREIRA, 2006), porém, essas duas formas de aprendizagem se complementam, pois a segunda pode levar à primeira. Muitas vezes, um indivíduo pode aprender mecanicamente e, somente mais tarde, perceber que esse aprendizado se relaciona com algum conhecimento anterior. Com o passar do tempo, tais conhecimentos ficam mais complexos e são capazes de servir de "âncora" para outros.

Existem algumas condições para que a aprendizagem significativa ocorra. A primeira é que, para ser considerado potencialmente significativo, o material a ser aprendido tenha estruturação lógica e possa se relacionar com a estrutura cognitiva do estudante, de maneira não arbitrária e não literal. Também é necessário que o aprendiz apresente uma disposição para aprender significativamente, de modo que ele não pode ter a intenção de memorizar ou decorar o material, sendo essa a segunda condição para a ocorrência da aprendizagem significativa. Quando uma das duas condições não for satisfeita, ocorrerá, segundo Ausubel (apud MOREIRA, 2006), uma aprendizagem mecânica.

Para facilitar a aprendizagem significativa, o teórico recomenda o uso de organizadores prévios, que consistem em materiais a serem propostos antes da utilização do material de aprendizagem propriamente dito, servindo de ponte entre o conhecimento prévio e os assuntos que se pretende ensinar. No decorrer da aprendizagem significativa, os conceitos que interagem com o novo conhecimento e servem de base para a atribuição de novos significados também vão se modificando em razão dessa interação, isto é, vão adquirindo novos significados e diferenciando-se progressivamente. A esse processo dinâmico da estrutura cognitiva denominase "diferenciação progressiva" (MOREIRA, 2006).

Outro processo que ocorre durante a aprendizagem significativa é o estabelecimento de relações entre conceitos subsunçores já constituídos na estrutura cognitiva. Os elementos nela 
Mapas conceituais: um curso de capacitação para professores da educação básica

existentes com determinado grau de clareza, estabilidade e diferenciação são combinados entre si para a aquisição de novos significados, originando uma reorganização dessa estrutura. Tal recombinação é chamada de "reconciliação integrativa".

Para promover integração, reconciliação e diferenciação de significados dos conceitos, Moreira (1999) apresenta os mapas conceituais como uma estratégia potencialmente facilitadora de uma aprendizagem significativa. Nas palavras do autor,

[...] mapas conceituais foram desenvolvidos para promover a aprendizagem significativa. A análise do currículo e o ensino sob uma abordagem ausebeliana, em termos de significados, implicam: 1) identificar a estrutura de significados aceita no contexto da matéria de ensino; 2) identificar os conceitos subsunçores (significados) necessários para a aprendizagem significativa na matéria de ensino; 3) identificar os significados preexistentes na estrutura cognitiva do aprendiz; 4) organizar sequencialmente o conteúdo e selecionar materiais curriculares, usando as ideias de diferenciação progressiva e reconciliação integrativa como princípios programáticos; 5) ensinar usando organizadores prévios, para fazer pontes entre os significados que o aluno já tem e os que ele precisaria ter para aprender significativamente a matéria de ensino, bem como para o estabelecimento de relações explícitas entre o novo conhecimento e aquele já existente e adequado para dar significados aos novos materiais de aprendizagem. (MOREIRA, 1999, p. 8).

Esses mapas são diagramas que indicam relações entre conceitos, ou entre palavras usadas para representar conceitos. Podem ser considerados um estruturador do conhecimento, na medida em que permitem mostrar como o conhecimento sobre determinado assunto está organizado na estrutura cognitiva de seu autor, que, assim, pode visualizar e analisar sua profundidade e extensão. Também, podem ser entendidos como uma representação visual utilizada para partilhar significados, pois explicam como o autor estabelece as relações e as hierarquizações entre os conceitos listados.

O curso objetivou oportunizar aos docentes da educação básica um momento para que pudessem colocar em reflexão o seu fazer pedagógico e, com base na dinâmica desenvolvida, implementar, em suas aulas, os princípios que fundamentam a concepção dos mapas conceituais. Em síntese, a atividade foi planejada como uma oportunidade de pensar e testar conhecimentos pedagógicos, por meio da negociação e do compartilhamento de novos significados desses conhecimentos para o exercício da atividade profissional.

\section{0 curso de extensão: os participantes e a metodologia utilizada}

A experiência relatada é fruto de uma das atividades desenvolvidas por dois professores extensionistas da Universidade de Passo Fundo (UPF), junto a um grupo de 18 professores da Educação Básica da rede pública estadual que ministram aulas de Matemática, Língua 
Mapas conceituais: um curso de capacitação para professores da educação básica

Portuguesa, Geografia, História e Ciências em instituições de ensino da região de Passo Fundo (RS), em um curso de capacitação de professores com duração de 20 horas, em cinco encontros.

No primeiro encontro, discutiu-se a teoria da aprendizagem significativa de Ausubel, de acordo com o que é apresentado por Moreira (1999), destacando que a sua ideia central consiste em descobrir o que o estudante já sabe e ensinar a partir desse conhecimento. Nessa etapa, apresentou-se a definição de conceitos subsunçores, organizadores prévios e aprendizagem mecânica, discutindo-se, na sequência, sobre as condições necessárias para se aprender significativamente e sobre como identificar indícios da aprendizagem significativa. $\mathrm{Na}$ continuidade, iniciou-se uma reflexão acerca do que é, da estrutura e das diferentes possibilidades de utilização de mapas conceituais como elemento capaz de auxiliar no processo de ensinar e aprender significativamente. Nessa parte do encontro construiu-se um mapa conceitual sobre a teoria da aprendizagem significativa de Ausubel onde buscou-se exemplificar a construção um mapa de conceitos e fortalecer os conceitos essenciais dessa teoria de aprendizagem.

No segundo, visando o fortalecimento da compreensão do que é um mapa conceitual e da sua elaboração, no início da atividade distribuiu-se aos participantes um artigo de Moreira (2005) no qual o autor sugere como elaborar e construir um mapa conceitual. Com base na leitura, salientou-se que é possível traçar um mapa conceitual para uma única aula, para uma unidade de estudo, para um curso, ou, até mesmo, para um programa educacional completo; a diferença estará no grau de generalidade e inclusividade dos conceitos colocados no mapa. Explicou-se, nessa perspectiva, que um mapa envolvendo apenas conceitos gerais, inclusivos e organizacionais pode ser usado como referencial para o planejamento de um curso inteiro, enquanto que um mapa incluindo somente conceitos específicos, pouco inclusivos, pode auxiliar na seleção de determinados materiais instrucionais. Isso quer dizer que mapas conceituais podem ser importantes mecanismos para focalizar a atenção do planejador de currículo na distinção entre conteúdo curricular e conteúdo instrumental, ou seja, entre o conteúdo que se espera que seja aprendido e aquele que serve de veículo para a aprendizagem. Como salienta Moreira (1999, p. 4):

[...] o conteúdo curricular está contido em fontes de conhecimento, tais como artigos de pesquisa, ensaios, poemas, livros. Mapas conceituais podem ser úteis na análise desses documentos a fim de tornar adequado para instrução o conhecimento neles contido. Considera-se aqui que o currículo se refere a um conjunto de conhecimentos. Sendo assim, a análise da estrutura do conhecimento implica a análise do currículo, e o mapeamento conceitual pode ser um instrumento útil nessa análise.

Nesse mesmo sentido, comentou-se que os mapas conceituais podem ser usados para mostrar relações significativas entre conceitos ensinados em uma única aula, em uma unidade 
Mapas conceituais: um curso de capacitação para professores da educação básica

de estudo, ou em um curso inteiro. Sendo representações concisas das estruturas conceituais que estão sendo ensinadas, é provável que esses recursos facilitem a aprendizagem dessas estruturas. Procurou-se deixar claro aos participantes que, diferentemente de outros materiais didáticos, mapas conceituais não são autoinstrutivos, necessitando ser explicados pelo professor, e que, embora possam ser usados para fornecer uma visão geral do tema em estudo, é preferível usá-los quando os estudantes já têm certa familiaridade com o assunto, de modo que sejam potencialmente significativos e permitam a integração, a reconciliação e a diferenciação de significados de conceitos (MOREIRA, 1980, 2010).

Ainda, no decorrer da discussão das potencialidades dos mapas conceituais, salientou-se que, ao utilizarem mapas conceituais para integrar, reconciliar e diferenciar conceitos, ou para analisar artigos, textos, capítulos de livros, romances, experimentos de laboratório e outros materiais educativos do currículo, os estudantes estarão aplicando o mapeamento conceitual como um recurso de aprendizagem. Em contrapartida, ao utilizarem mapas conceituais para obter uma visualização da organização conceitual que atribuem a um dado conhecimento, os aprendizes estarão destinando a esses materiais a função de instrumento de avaliação da aprendizagem. Nesse caso, tem-se, basicamente, uma técnica não tradicional de avaliação, mais apropriada para uma avaliação qualitativa, formativa, da aprendizagem, que busca informações sobre os significados e as relações significativas entre conceitos-chave da matéria de ensino, segundo o ponto de vista do estudante.

No final do encontro, após a reflexão que fundamenta a utilização do mapeamento conceitual, apresentou-se aos participantes o software Cmap Tools ${ }^{i}$ (CAÑAS et al., 2003). Esse programa, que possibilita construir mapas conceituais, também permite gravar todos os passos desse processo e reproduzir, a qualquer momento, dinamicamente, todas as modificações realizadas, possibilitando, por meio da comunicação/colaboração, a participação ativa de todos os envolvidos na construção. Dessa forma, viabiliza acompanhar a elaboração e a representação dos conceitos envolvidos no processo de aprender significativamente.

0 terceiro e o quarto encontro, destinaram-se para exemplificar/demonstrar/treinar, sugeriu-se aos participantes a construção de um mapa conceitual. Para tal, eles foram organizados em quatro grupos de quatro e cinco participantes cada. Inicialmente, no terceiro encontro os grupos receberam o artigo de autoria de Rosa, Darroz e Rosa (2014), intitulado "Estudo das rampas para cadeirante: uma proposta de tema interdisciplinar para o ensino médio". Partindo da leitura e de um breve comentário oral de todos os participantes, os grupos foram convidados a elaborar a primeira versão do mapa conceitual dos tópicos contidos no artigo. As Figuras 1 e $\mathbf{2}$ expõem as versões iniciais dos mapas produzidos pelos grupos no decorrer do curso. 
Mapas conceituais: um curso de capacitação para professores da educação básica

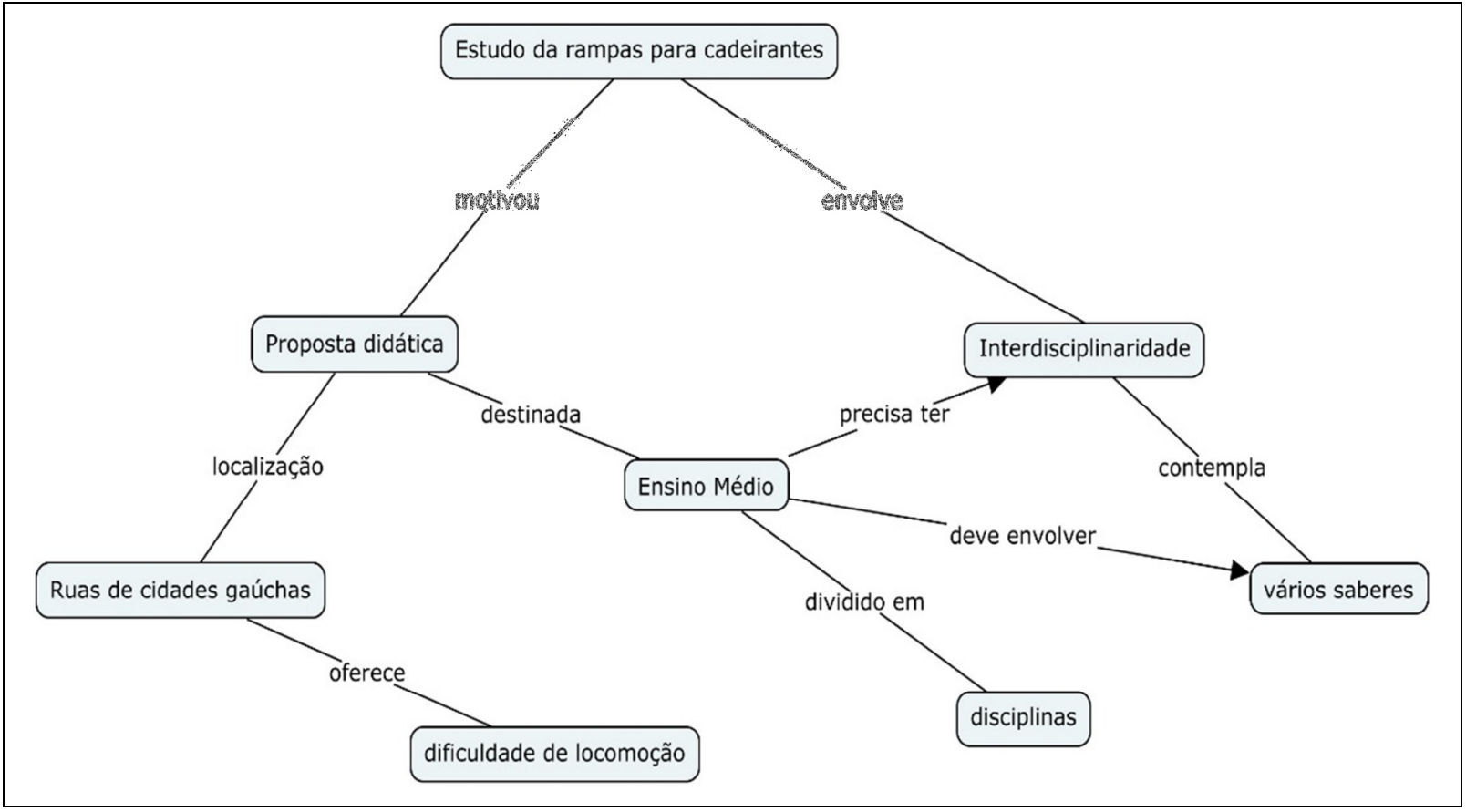

Figura 1: Primeira versão do mapa conceitual produzido pelo grupo 1

Fonte: Elaboração própria.

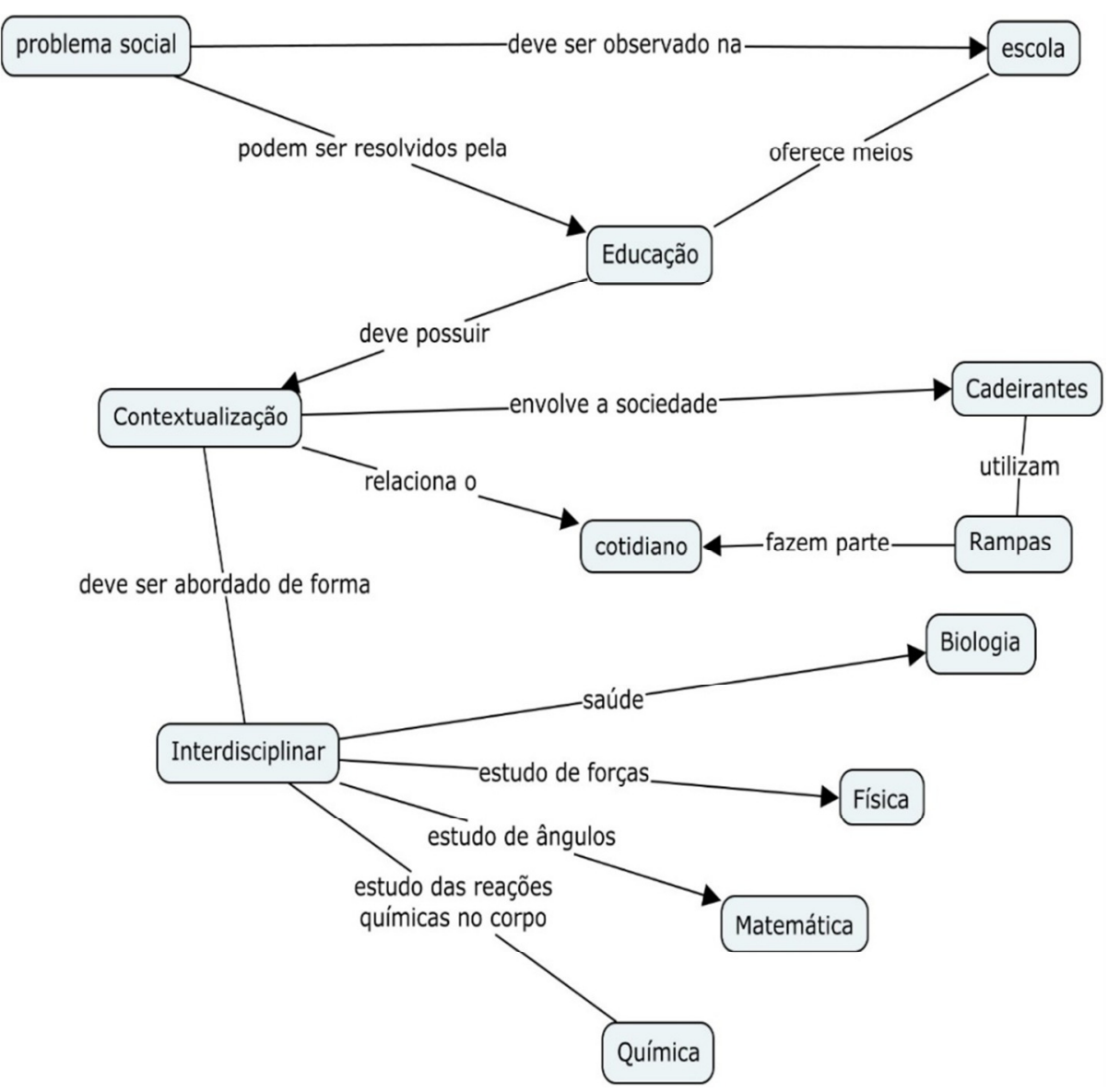

Figura 2: Primeira versão do mapa conceitual produzido pelo grupo 2

Fonte: Elaboração própria. 
Mapas conceituais: um curso de capacitação para professores da educação básica

No quarto encontro cada grupo apresentou a versão inicial ao grande grupo e, após, se julgassem necessário, poderiam reformulá-la. A intenção era que os participantes reorganizassem e adquirissem novos significados, promovendo a diferenciação progressiva e a reconciliação integrativa, e que o conhecimento abordado se ancorasse em um possível conceito subsunçor. As Figuras 3 e 4 expõem as versões reformuladas dos mapas produzidos pelos grupos.

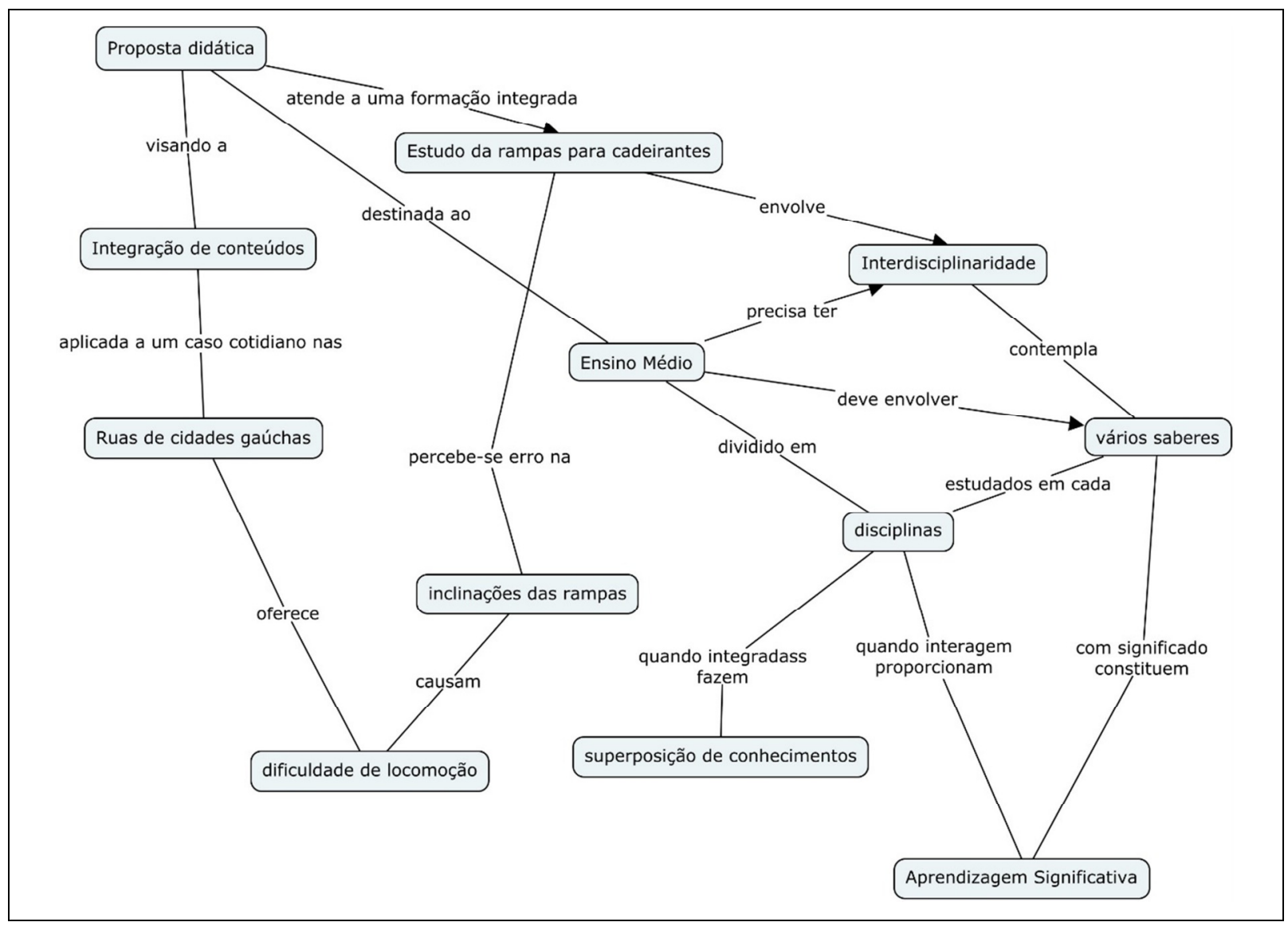

Figura 3: Segunda versão do mapa conceitual produzido pelo grupo 1

Fonte: Elaboração própria. 
Mapas conceituais: um curso de capacitação para professores da educação básica

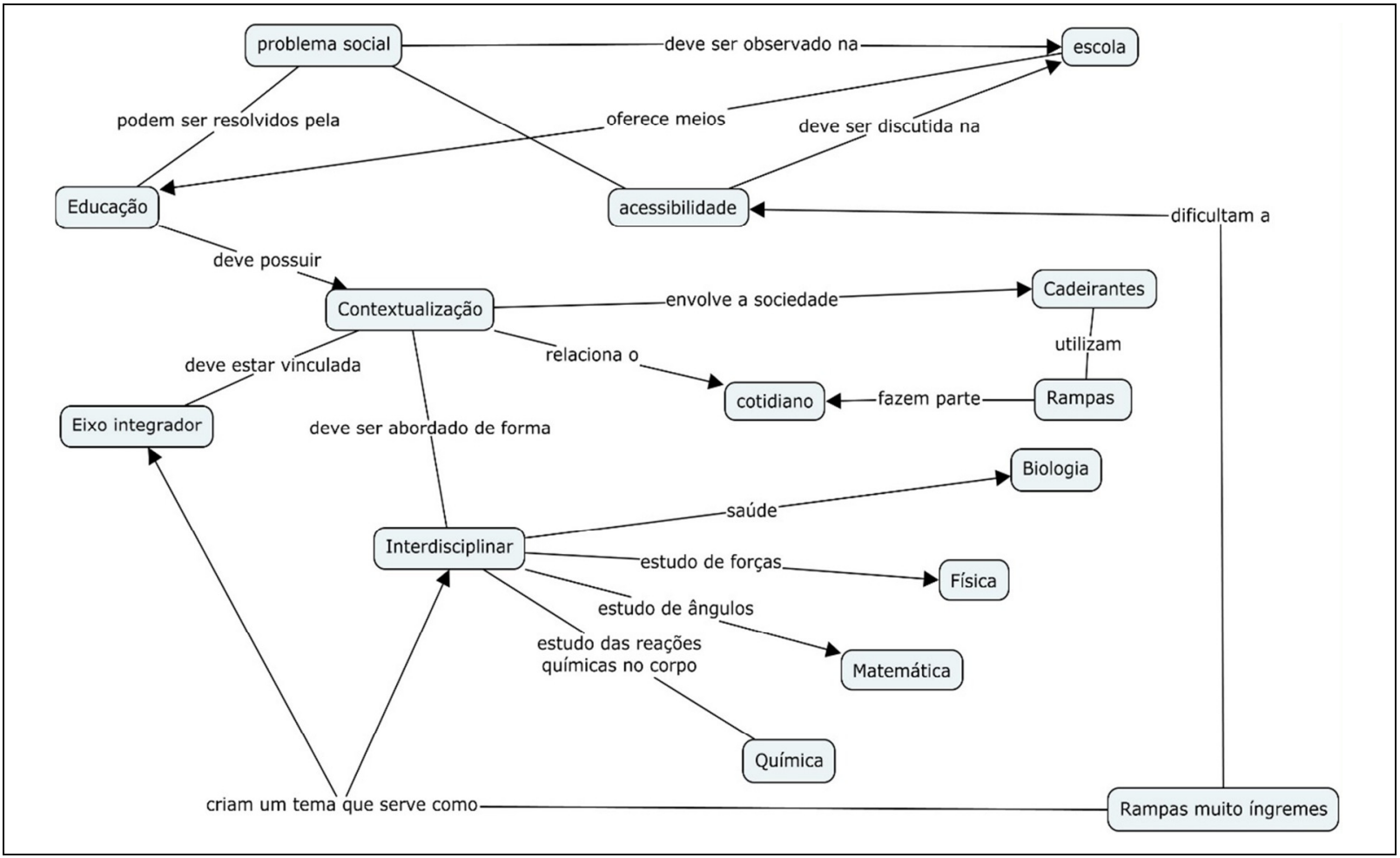

Figura 4: Segunda versão do mapa conceitual produzido pelo grupo 2.

Fonte: Elaboração própria.

O quinto e último encontro teve como objetivo a discussão de que o mapeamento conceitual pode levar a profundas modificações na maneira de ensinar, de avaliar e de aprender e, em razão disso, ser usado em diversas situações do processo de ensino-aprendizagem como instrumento de análise do currículo, técnica didática, recurso de aprendizagem, meio de avaliação (MOREIRA; BUCHWEITZ, 1993). Assim, debateu-se como se daria a identificação dos conceitos subsunçores através do uso de mapas conceituais, quais os critérios que seriam necessários para avaliar um conteúdo por meio do mapeamento conceitual e, que tal metodologia, também pode servir para apresentar assuntos que serão estudados.

\section{Avaliação dos mapas construídos durante o curso}

Ao analisar e comparar as versões iniciais e finais dos mapas elaborados no decorrer do curso, buscou-se identificar indícios que pudessem confirmar se a metodologia utilizada foi capaz de promover uma organização hierárquica dos conceitos abordados na estrutura cognitiva dos participantes. Além disso, procurou-se verificar se a forma como os participantes dispuseram e relacionaram os tópicos nos mapas apontam uma diferenciação progressiva e uma reconciliação integrativa capazes de proporcionar uma aprendizagem significativa dos temas 
Mapas conceituais: um curso de capacitação para professores da educação básica

estudados. No entanto, o principal objetivo consistia em demonstrar aos participantes uma das estratégias em que a metodologia do mapeamento conceitual pode ser utilizada.

A versão inicial dos mapas construídos apresentou os principais conceitos abordados no artigo, porém, a conexão linear apresentada, somada à má exploração de conectores adequados, demonstrou que os participantes tiveram dificuldades em perceber, nitidamente, as relações entre esses conceitos. Acredita-se que a própria falta de hábito em construir mapas conceituais tenha sido o principal obstáculo enfrentado pelo grupo. É importante destacar que, durante o processo de construção dos mapas, os professores não tinham muita clareza sobre quais eram os conceitos relevantes e as conexões existentes entre os assuntos abordados. Por esse motivo, necessitavam reler constantemente o artigo e, assim, apropriar-se de novos significados relacionados com os conceitos estudados para elaborar o mapa. Entende-se que esse ir e vir entre o material instrucional e a construção do mapa possibilitou-lhes uma reelaboração conceitual.

Nas comparações, notou-se uma significativa melhora entre as versões iniciais e finais, a qual se atribui aos momentos de apresentação e discussão dos mapas. Essas ocasiões, que se constituíram em um período importante da oficina, proporcionaram, durante a explanação de cada grupo, oportunidades para que os colegas participassem com críticas e sugestões de alterações nos mapas e compartilhassem novos significados, somando-os ao que estavam estudando. Nas apresentações, houve debate e discussão, o que contribuiu significativamente para a melhor elaboração dos mapas finais, fortalecendo a aprendizagem significativa.

Nas versões finais, houve a manutenção da ordem hierárquica dos conceitos, em termos de importância, com ampliação do número de conceitos fundamentais. Nessas versões, ocorreram desdobramentos de conceitos mais globais em outros menos inclusivos, indicando a capacidade dos participantes em realizarem a diferenciação conceitual progressiva. Observouse, ainda, inserção de novos elos entre tópicos de ramos conceituais distintos, ou seja, determinados conceitos foram relacionados com outros aparentemente diferentes, demonstrando que os participantes conseguiram, também, promover a reconciliação integrativa dos temas abordados.

Além disso, foi possível perceber que as discussões sobre as diferentes situações de ensino que podem fazer uso do mapeamento conceitual foram muito satisfatórias. 0 grupo participante sempre apresentou sugestões de novas possibilidades da utilização dessa metodologia, o que demonstra que o tema foi assimilado por sua estrutura cognitiva. 


\section{Considerações finais}

Os resultados da experiência aqui descrita fomentam a hipótese de que uma metodologia com enfoque em um conteúdo significativo ao aprendiz é fundamental para despertar-lhe o prazer pela ciência, a construção de significado e a valorização do que está sendo aprendido. Quando a metodologia é desenvolvida para um grupo de professores que percebem sua ligação direta com o que estão vivenciando e a interpretam como importante para suas vidas, passa-se a desenvolver um potencial ainda maior para a aprendizagem. Dessa forma, a oficina de formação continuada sobre a utilização de mapas conceituais no processo de ensinar e aprender conceitos científicos pode ser considerada uma experiência bem-sucedida em vista do objetivo de complementar os currículos dos cursos de formação de professores.

Por tudo isso, mesmo aparentemente simples e, às vezes, confundidos com esquemas ou diagramas organizacionais, os mapas conceituais são instrumentos que podem levar a profundas modificações na maneira de ensinar, de avaliar e de aprender (MOREIRA, 1999). Uma vez que procuram promover a aprendizagem significativa e entram em choque com técnicas voltadas para aprendizagem mecânica, utilizá-los em toda sua potencialidade implica atribuir novos significados aos conceitos de ensino, aprendizagem e avaliação.

\section{Referências}

CAÑAS, A. J. et al. Cmap Tools: a knowledge modeling and sharing toolkit, technical report IHMC Cmap Tools 93-01. Institute for Human and Machine Cognition, 2003.

MOREIRA, M. A. Mapas conceituais como instrumentos para promover a diferenciação conceitual progressiva e a reconciliação integrativa. Ciência e Cultura, v. 32, n. 4, p. 474-479. 1980.

MOREIRA, M. A. Teorias de aprendizagem. São Paulo: EPU, 1999.

MOREIRA, M. A. Mapas conceituais e aprendizagem significativa. Revista Chilena de Educação Científica, v. 4, n. 2, p. 38-44, 2005.

MOREIRA, M. A. Mapas conceituais e diagramas V. Porto Alegre: Ed. do autor, 2006.

MOREIRA, M. A. Mapas conceituais e aprendizagem significativa. São Paulo: Centauro, 2010.

MOREIRA, M. A; BUCHWEITZ, B. Novas estratégias de ensino e aprendizagem: os mapas conceituais e o Vê epistemológico. Lisboa: Plátano Edições Técnicas, 1993.

NEVES, C. M. C. A Capes e a formação de professores para a educação básica. Revista Brasileira de Pós-Graduação, Brasília, supl. 2, v. 8, n. 16, p. 353-373, mar. 2012. 
Mapas conceituais: um curso de capacitação para professores da educação básica

ROSA, C. T. W.; DARROZ, L. M.; ROSA, A. B. Estudo das rampas para cadeirantes: uma proposta de tema interdisciplinar para o ensino médio. Espaço Pedagógico, 2014.

i Disponível em: <http://cmap.ihmc.us/>. Acesso em: 17 set. 2015.

Conceptual maps: a training course for primary education teachers

\section{ABSTRACT}

This work presents a successful experience of teacher training. It is an extension course, performed with a group of primary education teachers, which aimed to present/reinforce the method of conceptual mapping to promote the significant learning of concepts worked in the classroom. The course consisted of five meetings, and the results reinforce the assumption that a methodology focused on content that is significant for teachers is essential to spark the interest in new methodological learning processes, which will help teachers to construct the meaning of the lesson proposed.

\section{Keywords}

Conceptual mapping; Significant learning; Teacher training.

Original submetido em: 17 set. 2015

Aceito para publicação em: 15 nov. 2015

\author{
Mapas conceptuales: un curso de \\ capacitación para profesores de la educación \\ primaria
}

\section{RESUMEN}

Este trabajo presenta una experiencia de capacitación docente. Se trata de un curso de extensión realizado con un grupo de profesores de la educación primaria cuyo objetivo era presentar/fortalecer la metodología de mapeo conceptual para la promoción del aprendizaje significativo de los conceptos trabajados en clase. El curso se hizo en cinco encuentros, y los resultados fortalecieron la suposición de que una metodología con enfoque en un contenido significativo para el profesor es fundamental, porque despierta el interés por nuevos aprendizajes metodológicos que lo ayuden en la construcción del significado de lo que pretende enseñar.

\section{Palabras clave}

Mapas conceptuales; Aprendizaje significativo; Capacitación de profesores.

Sobre os autores:

\section{Luiz Marcelo Darroz}

Graduado em Matemática e Especialista em Física pela Universidade de Passo Fundo; Mestre em Ensino de Física pela Universidade Federal do Rio Grande do Sul; Licenciando em Física pela Universidade Federal de Santa Maria e Doutorando em Educação em Ciências pela Universidade Federal do Rio Grande do Sul..

\section{Jucelino Cortez}

Graduado em Matemática pela Universidade de Passo Fundo e Mestre em Ensino de Física pela Universidade Federal do Rio Grande do Sul. 